\title{
NUEVO FINANCIAMIENTO NACIONAL PARA LA VIVIENDA: CARACTERÍSTICAS E IMPLEMENTACIÓN DE LOS CRÉDITOS HIPOTECARIOS UVA EN ROSARIO
}

\author{
NEW NATIONAL FINANCING FOR HOUSING: CHARACTERISTICS AND IMPLEMENTATION OF THE UVA \\ MORTGAGE LOANS IN ROSARIO
}

Cintia Ariana Barenboim ${ }^{1}$

\section{Resumen}

Uno de los mayores problemas que tiene Argentina es la dificultad del acceso a la vivienda propia para los sectores medios. Si bien los créditos hipotecarios pueden ser una solución, no han tenido una gran participación, representando solo el 1,5\% del PBI en el 2012. En respuesta, ese mismo año se lanzó el "Programa Pro.Cre.Ar" limitado parcialmente por el nuevo gobierno en 2016 que crea otro sistema de financiamiento basado en la "Unidad de Valor Adquisitivo" (UVA), actualizado con el Coeficiente de Estabilización de Referencia regido por el índice general de inflación.

En este contexto el objetivo principal del artículo radica en analizar el nuevo sistema de financiamiento público UVA para obtener una vivienda propia en Rosario. La metodología es descriptiva, centrada en el análisis de contenido de documentos escritos (investigaciones, artículos periodísticos, documentos oficiales) y realización de entrevistas semi- estructuradas.

\footnotetext{
${ }^{1}$ Cintia Ariana Barenboim es Arquitecta (FAPyD-UNR), Magíster en Planificación Urbana - Regional (FADU-UBA) y Doctora en Geografía, orientación urbana (FILO-UBA). Posdoctorado en segregación socioespacial y valoración inmobiliaria (CURDIUR-UNR). Investigadora Asistente del CONICET. Docente Titular de Planeamiento y Urbanismo (FCEIA-UNR), Enfoques Socio-antropológico del Habitar, Análisis del Mercado Inmobiliario y Estrategias de Inversión (FA-UAI). Directora y co-directora de trabajos de investigación radicados en el Centro de Alto Estudios Arquitectura (UAI), Secretaria de Ciencia y Técnica (UNR) y Lincoln Institute of Land Policy. Codirectora de tesis académicas. Asesoró al Concejo Deliberante de Rosario, la Dirección de Habilitación de Industrias, Comercios y Servicios de la Municipalidad de Rosario y la Subsecretaria de Desarrollo Urbano y Vivienda de la Nación. Realizó cursos de capacitación profesional en el Lincoln Institute of Land Policy. $3^{\circ}$ Premio Investigadores en Formación ARQUISUR 2009. Autora de diversas publicaciones locales e internacionales. Universidad Nacional de Rosario - Argentina. ORCID iD: $\quad h$ ttp://orcid.org/0000-0001-8889-2776 $\quad$ E-mail:
} arq.barenboim@gmail.com 
Los resultados muestran que en sus comienzos no tuvo problemas, las cuotas eran bajas (similares a la de un alquiler) y los bancos públicos tuvieron mayor protagonismo pero desde el 2018 con la acelerada inflación, la devaluación de la moneda, los consecuentes incrementos de las UVA y tasas fijas hicieron que la demanda se redujera, prácticamente no habiendo solicitudes. Los resultados muestran que en sus comienzos no tuvo problemas, las cuotas eran bajas (similares a la de un alquiler) y los bancos públicos tuvieron mayor protagonismo pero desde el 2018 con la acelerada inflación, la devaluación de la moneda, los consecuentes incrementos de las UVA y tasas fijas hicieron que la demanda se redujera, prácticamente no habiendo solicitudes.

Palabras clave: políticas habitacionales, crédito hipotecario, vivienda propia, sectores medios, Rosario.

\begin{abstract}
One of the biggest problems that Argentina has is the difficulty of access to own housing for the middle sectors. Although mortgage loans can be a solution, have not had a large participation, representing only $1.5 \%$ of GDP in 2012. In response, that same year the "Pro.Cre.Ar Program" was partially launched, which was then limited by the new government in 2016 that creates another financing system based on the "Purchase Value Unit" (UVA), updated with the Reference Stabilization Coefficient governed by the general inflation index.

In this context, the main objective of the article is to analyze the new UVA public financing system to obtain a home of its own in Rosario. The methodology is descriptive, focused on the content analysis of written documents (research, journalistic articles, official documents) and semi-structured interviews.

The results show that in its beginnings it did not have problems, the quotas were low (similar to that of a rent) and the public banks had greater protagonism but since 2018 with the accelerated inflation, the devaluation of the currency, the consequent increases of the UVA and fixed rates caused the demand to be reduced, with practically no requests.
\end{abstract}

Keywords: housing policies, mortgage credit, own housing, middle sectors, Rosario. 


\section{INTRODUCCIÓN}

En Argentina el desarrollo inmobiliario no se produjo por una expansión del sistema de financiamiento, teniendo los créditos hipotecarios una participación pequeña con respecto a otras naciones de América Latina, representando solo el 1,5\% del PBI en el año 2012 (Tessmer y otros, 2018). La expansión del mercado se dio a través de inversiones del sector agropecuario y de los estratos sociales de más altos ingresos, que debido a la crisis de comienzos de siglo (corralito financiero) poseen una desconfianza en el sistema financiero y destinan sus fondos a la industria de la construcción. Los bienes inmuebles se comportaron como un activo financiero produciendo, por un lado, grandes ganancias y por otro, un incremento más que significativo en el precio.

La vivienda lejos de tener un fin social tuvo entonces un fin netamente financiero. El acceso a la vivienda para los sectores medios y bajos resultó cada vez más difícil, ante el escaso financiamiento y la valorización de la misma en las ciudades. Las respuestas que brindó el gobierno nacional fuerón usualmente de dos maneras: del lado de la oferta, directa a través de la ejecución del loteo, la construcción o mejoramiento de la vivienda, y del lado de la demanda, indirecta cuando subsidia los créditos hipotecarios, de la construcción y/o ampliación (Barenboim, 2017). Cabe señalar que la mayoría de los fondos se destinarón a la construcción de viviendas nuevas, debiendo repensar políticas que reconozcan el variado abanico de necesidades de la problemática (Gargantini, 2015).

A pesar de que se implementan iniciativas vinculadas al control de precios de los materiales, a la reglamentación del mercado de alquileres o al establecer los indicadores de ocupación y usos de suelo en los Códigos Urbanos (Pérez Barreda, 2015), de ningún modo el Estado logra regular el mercado de suelo urbano siendo este un elemento central para el acceso al suelo y a la vivienda (Barenboim, 2017).

El programa nacional Pro.Cre.Ar lanzado en el año 2012 representó una esperanza para los sectores medios, en donde se otorgaron seis líneas de créditos, vinculado principalmente con la construcción de vivienda y generación de empleo, siendo el subsidio mayor. Sin embargo, con el nuevo gobierno nacional a fines del año 2015 se bajó el subsidio, orientándose a la compra de viviendas terminadas y no a la producción sumado a la fuerte caída de actividad del sector de la construcción. 
En consecuencia, en abril de 2016 el Estado a través de normativas del Congreso y el Banco Central de la República Argentina (BCRA), realiza cambios en la regulación de un conjunto de instrumentos financieros orientados a reactivar el crédito hipotecario y el ahorro en moneda nacional a largo plazo dentro del contexto inflacionario vigente, ya desde hace más de una década. En este sentido se propone una nueva unidad para créditos "Unidad de Vivienda" (UVI), actualizada con el Índice del Costo de Construcción publicado por el INDEC, y otra denominada "Unidad de Valor Adquisitivo" (UVA), referenciada por la evolución del Coeficiente de Estabilización de Referencia (CER) regido por el índice general de inflación.

La implementación de este tipo de política demuestra el interés y la importancia que esta temática merece, constituyendo una adaptación de las experiencias de otros países de América Latina. En Chile con la creación de la Unidad de Fomento (UF) en el año 1967, Colombia con la Unidad de Valor Real (UVR) en 2000, Bolivia con la aplicación de la Unidad de Fomento Vivienda (UFV - 2001) y Uruguay con la unidad indexatoria a partir del año 2011 (Camusso, Thailinger y Villaggi, 2018:8).

Sin embargo, la potenciación de los créditos hipotecarios tuvo un breve auge, solo dos años, hasta principios del 2018, cuando fueron impactados por una fuerte devaluación de la moneda local y creciente inflación, entre otras cuestiones vinculadas al ámbito macroeconómico. La delicada situación actual aleja a las familias de adquirir la vivienda propia, quienes suelen contar con limitados ahorros, con una relación cuota/ingreso desfasada y necesitando un mayor plazo para poder realizar la compra inmobiliaria.

En este contexto, el objetivo principal se basa en continuar profundizando en las formas de acceso a la vivienda propia para los sectores medios en Rosario, describiendo las políticas públicas implementadas por el gobierno nacional, a partir del nuevo instrumento de financiamiento "Créditos UVA“, durante el período 2016 - 2019. De esta manera se podrá detectar los puntos críticos y las posibles alternativas, pudiendo contribuir en futuras políticas y/o herramientas. Especialmente la investigación se aboca a la clase media diferenciándose de la clase alta que tiene el problema de la vivienda resuelto, ya que no necesita financiamiento, y de la clase baja que el Estado contiene parcialmente con planes sociales específicos (Paredes y otros, 2014). Es decir que la clase media es el sector postergado, no habiendo tenido respuestas del Estado durante varios años.

Los objetivos particulares que se proponen son tres. Primero describir concisamente la Unidad de Valor Adquisitivo (UVA): objetivo, beneficiarios, montos. Segundo, evaluar los cambios durante su 
gestión y las adaptaciones ejecutadas para Rosario. Por último, identificar cuál fue su alcance en la ciudad de Rosario (ubicación, cantidad de solicitudes y prototipos).

Por último, en cuanto la metodología, la investigación es de tipo descriptiva buscando exponer y analizar la nueva modalidad de financiamiento nacional aplicada sobre el caso Rosario. Esta se centra en el análisis de contenido de documentos escritos (documentos oficiales, investigaciones, artículos periodísticos). Para completar la información se recurre a la realización de entrevistas semiestructuradas a los actores involucrados (beneficiarios, inmobiliarias, banqueros).

\section{BREVE MARCO TEORICO CONCEPTUAL}

La "vivienda digna" para la población es un derecho declarado en la Constitución Argentina, a pesar de que no siempre se cumpla. Esta comprende su habitabilidad, calidad constructiva, asequibilidad (tanto en el precio de la vivienda como en alquiler), infraestructura básica, emplazamiento en áreas seguras y seguridad en la tenencia jurídica (Barreto, 2010).

Lo antedicho son los factores básicos que una vivienda, más allá de las particularidades de su emplazamiento y su medio (geográfico, social y cultural), deberían poseer para cumplir con los criterios de adecuación que satisfagan las necesidades básicas de sus habitantes en un contexto determinado (Lazzari, 2012: 6).

La brecha entre los requerimientos (problema de habitabilidad o falta de vivienda) y la disponibilidad de viviendas adecuadas para un sector de la sociedad, es decir lo que el Celade (2010:2) determina como el "déficit habitacional", es cada vez mayor y con una persistencia crónica en el tiempo.

El capital privado hasta cierto punto manipula y controla la oferta y la demanda de inmuebles en la ciudad (Harvey, 2012). El mercado inmobiliario es restrictivo, aun para aquellos sectores sociales que no son marginales y que tienen capacidad de pago como los sectores medios, dando cuenta de la necesidad de resolver las distintas situaciones para que puedan acceder a una vivienda.

En este contexto, el Estado es el actor principal, contando con una participación fundamental para asegurar el desarrollo de políticas públicas que permitan la reducción del déficit habitacional. A su vez, puede incorporar criterios de planificación urbana equitativos, regular precios del mercado 
inmobiliario, aplicar instrumentos de promoción y compensación, subsidiar créditos hipotecarios, entre otros campos de su competencia.

Particularmente, el crédito hipotecario es un préstamo que se hace a largo plazo, respaldado por la hipoteca de la casa que se compra. El banco otorga una cantidad de dinero al beneficiario que lo devuelve mediante cuotas periódicas, junto con los intereses asociados, no debiendo representar más de cierto porcentaje de sus ingresos (Chanchona Rojas y De León Martínez, 2006). El financiamiento remarca el problema de la valorización de la vivienda por encima de la capacidad de pago de un sector importante de la población, en donde los intereses de los agentes privados, intervinientes en el mercado inmobiliario, son los que predominan (Domínguez y otros, 2017).

Al elegir el tipo de crédito para una vivienda hay que considerar la forma en que los beneficiaros recibirán los ingresos a largo plazo. Al respecto Chanchona Rojas y De León Martínez (2006:19) expresan dos maneras:

- si el ingreso crecer en el tiempo por mejoras laborales se recomienda tomar pagos pequeños en el principio y que estos puedan ir creciendo.

- si el ingreso va a quedar igual o podría bajar asegurarse un crédito con pagos que no vayan a subir con el tiempo y se tenga certezas en las tasas.

Por último, es importante conocer los factores de riesgo dado que pueden contribuir a la pérdida del crédito y/o de la propiedad. Estos son heterogéneos, pero pueden identificarse en dos grupos según (Chanchona Rojas y De León Martínez, 2006). Por un lado, los factores internos que dependen de la administración propia y de la capacidad propia de cada institución prestamista (cantidad de solicitudes, políticas y cambios en los créditos). Por el otro, los factores externos referidos a cuestiones macroeconómicas externas a las instituciones (inflación, depreciaciones de la moneda local, desastres naturales, entre otros).

\section{MODALIDAD DE FINANCIAMIENTO}

A partir del 2016, el gobierno nacional dispuso la implementación de nuevas modalidades de depósitos y préstamos para ahorrar con protección del poder adquisitivo y cumplir con el acceso a la vivienda propia de las familias que anteriormente alquilaban. Sanciona la Ley $N^{\circ} 27.271$ de Sistema para el Fomento de la Inversión en Vivienda, cuyos objetivos son: a) estimular el ahorro en moneda 
nacional a largo plazo; b) disminuir el déficit habitacional; y c) promover el crecimiento económico y el empleo a través de la inversión en vivienda.

Con esta iniciativa, en un esquema de cooperación, se combina el crédito hipotecario, el ahorro de las familias y una bonificación del Estado. El gobierno se compromete en aspectos institucionales actuando como impulsor y luego regulador de un mercado cuyos agentes delinearían la forma final de los productos a intercambiar, es decir las unidades habitacionales.

Para ello el BCRA, junto a otros bancos públicos y privados, ofrece dos líneas de crédito para la compra de vivienda nueva/usada, cambio, construcción y ampliación. Estas se caracterizan por cuotas más bajas que los créditos tradicionales, a largo plazo de cancelación (entre 15 y 30 años), actualizadas con distintos índices, y de rápido acceso. Al respecto Arbia (2017) asegura que se tarda en promedio entre 30 a 45 días en obtenerlos, desde que se presenta la documentación en el banco hasta el otorgamiento.

El público al cual está destinado son ciudadanos argentinos o con residencia permanente en el país que no sean beneficiarios de otro programa. Deben tener una edad entre 18 y 60 años, contar con los tres últimos recibos de sueldo, pensiones o jubilación; la cuota mensual a pagar puede cubrir hasta el $30 \%$ del ingreso neto familiar y no tener antecedentes negativos en el sistema financiero. Los trabajadores en relación de dependencia, que poseen cuenta sueldo en algún banco adherido, son los principales beneficiarios. Usualmente las edades de quienes solicitan estos créditos están entre los 35 y los 45 años, tratándose en su mayoría de parejas que suman sus ingresos para poder acceder a la vivienda propia (Barenboim, 2019).

\section{Unidades de medida}

El BCRA, basado en la Ley $N^{\circ} 27.271 / 16$, propone nuevas unidades para créditos siendo, según Tessmer, G. y otros (2018:4): “... una moneda artificial basada en el peso, diseñada para que cumpla con una de las funciones que la moneda local no puede cumplir por si sola la de ser reserva de valor". La captación-suscripción, liquidación-rescate y desembolso-cancelación, deberán realizarse siempre en pesos equivalentes a dicha unidad en fecha determinada (Camusso, Thailinger y Villaggi, 2018). En este sentido se crean dos instrumentos distintos de ahorro y préstamo: 
- Unidad de Vivienda (UVI) actualizada con el Índice del Costo de Construcción del Instituto Nacional de Estadística y Censos (INDEC) para vivienda unifamiliar modelo $6 .^{2}$ De forma tal que 1.000 UVIs serán equivalentes a un metro cuadrado (1.000 UVIs $\left.=1 \mathrm{~m}^{2}\right)$.

- Unidad de Valor Adquisitivo (UVA) referenciada diariamente por la evolución del Coeficiente de Estabilización de Referencia (CER) regido por el índice general de inflación. Dicho índice está basado en el de precios del consumidor que tiene una altísima correlación con el costo de construcción, pero sufre una volatilidad menor. De este modo 1.000 UVA serán equivalentes a un metro cuadrado $\left(1.000\right.$ UVA $\left.=1 \mathrm{~m}^{2}\right) .^{3}$

Las unidades UVA y UVI solo se diferencian por el índice a considerar al momento de su actualización y su valor diario es publicado por el BCRA en su página web. ${ }^{4}$ La finalidad que se persigue es: "... la de expresar los precios de transacciones de largo plazo en moneda local (el peso), para desacoplarlas de las variaciones de una extranjera (el dólar). La dificultad es que el flujo de ingresos de los potenciales tomadores de crédito, se encuentra expresados en pesos $y$, por tanto, no necesariamente ajustan a la misma velocidad o nivel..." (Tessmer, G. y otros 2018:4).

Gráfico 1. Valor de las Unidades UVI y UVA

\footnotetext{
${ }^{2}$ La Vivienda Unifamiliar Modelo 6 consta de una sola planta con dos dormitorios. Su superficie total es de 96,47 $\mathrm{m}^{2}$ : superficie cubierta de $80,80 \mathrm{~m}^{2}$ y superficie semi-cubierta de $15,67 \mathrm{~m}^{2}$.

${ }^{3}$ La fecha de implementación fue el 31 de marzo 2016, con un valor base inicial de \$14,05.

${ }^{4}$ http://www.bcra.gob.ar/PublicacionesEstadisticas/Principales variables.asp
} 


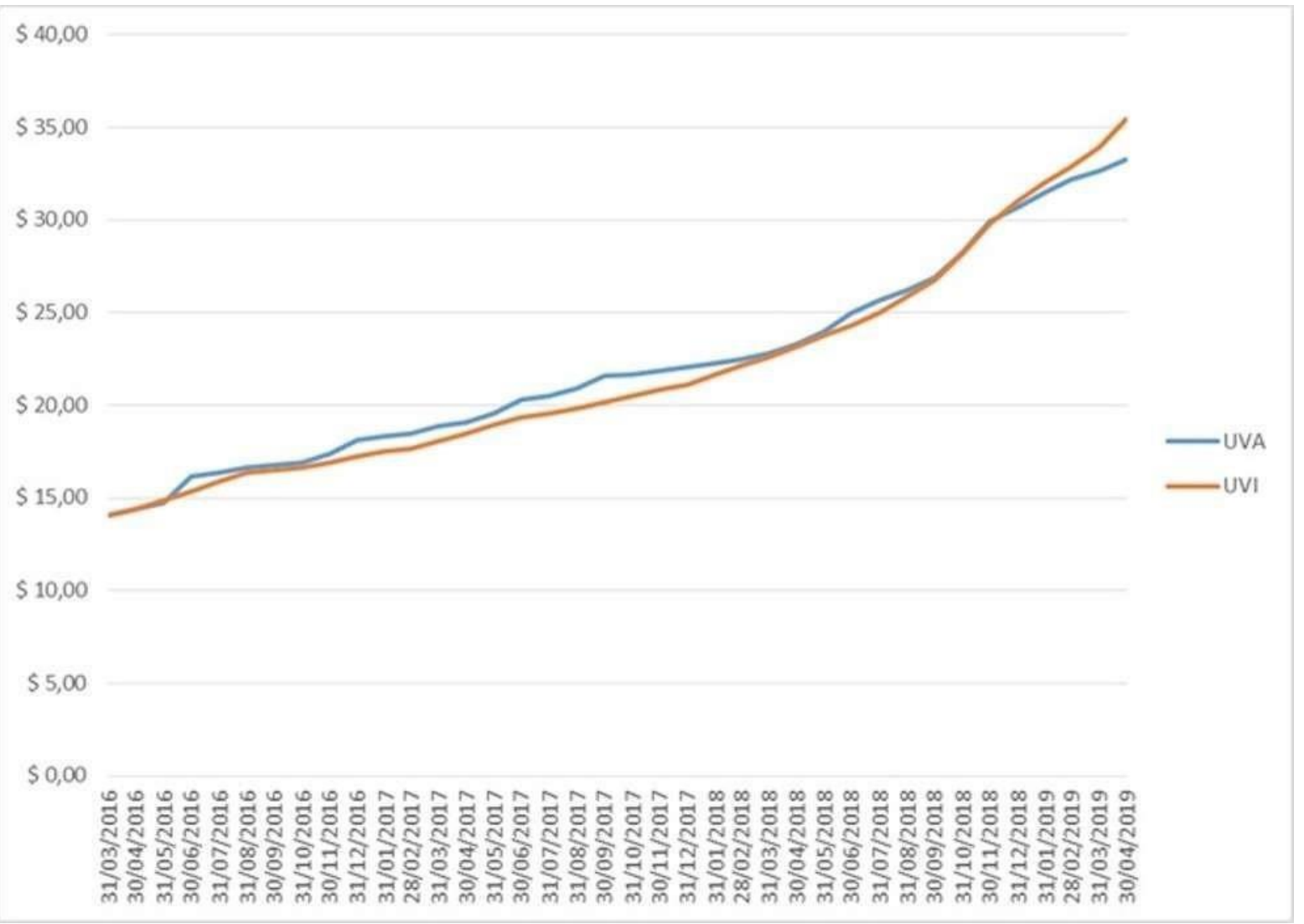

Fuente: elaboración propia en base a datos BCRA, 2019.

La evolución de los valores de las nuevas unidades, junto a la oferta y la demanda del mercado inmobiliario, determinan cual será la seleccionada por los beneficiarios. A poco de la implementación de la normativa se evidencia una diferencia entre los valores, teniendo una cuantía mayor la unidad UVI sobre la UVA durante los tres primeros años, revirtiéndose en los primeros meses del 2019 (Gráfico 1). Al respecto Camusso, Thailinger y Villaggi (2018:7) exponen que:

\begin{abstract}
"Hay una mayor volatilidad en el valor de la UVI, hecho que evidenciaría la preferencia por la denominación en UVA, cuya evolución es más suave a lo largo deltiempo dado que sigue laevolución de los precios de una canasta de consumo de referencia. En cambio para la UVI, se consideran sólo los precios de insumos yservicios relacionados alsector construcciónque, porejemplo, muestransaltos significativos al cierre por negociaciones salariales para el sector".

Esper (2018) agrega que “... generalmente se optó por el sistema de UVA tal vez creyendo que se trataba de una unidad más protectora del préstamo
\end{abstract}


bancario, pensando que el índice de la inflación sería más preciso que el de la construcción". Lo antedicho ha generado que los créditos otorgados en Rosario estén nominados en su totalidad en UVA encontrando solo material de estas unidades para su análisis en la ciudad.

\section{Características de préstamos}

Los créditos UVA son ofrecidos por trece bancos, de los cuales tres son públicos. Está orientada para:

- Adquisición de vivienda única y de ocupación permanente.

- Cambio de vivienda única y de ocupación permanente.

- Construcción en terreno propio de vivienda única y de ocupación permanente. ${ }^{5}$

- Ampliación, refacción o terminación de vivienda única y de ocupación permanente (Banco Nación, 2019).

El préstamo cubre hasta el $80 \%$ del valor de compra o tasación de una vivienda, que varía según el banco, lo que hace requerir de un ahorro previo mínimo del $20 \%$ del valor de la propiedad. Por ejemplo en el Banco Nación es de $\$ 4.700 .000$ para el año 2019. El monto máximo será de $\$ 3.760 .000$ y el monto mínimo de $\$ 250.000$ con un plazo para su cancelación de hasta 30 años. En el caso de ampliación, refacción o terminación el monto máximo será menor de $\$ 1.500 .000$ con un plazo hasta 10 años. Cabe señalar que dichas cifras inicialmente eran menores y se fueron actualizando debido a la inflación y el incremento del valor de los inmuebles durante estos últimos años (Banco Nación, 2019).

El capital residual y las cuotas pactadas en UVA tendrán una tasa real de interés que se mantendrá durante todo el crédito. Es decir que se ajustan por inflación y además tienen una tasa de interés fija, menor a la de los créditos tradicionales en donde el banco consideraba un escenario inflacionario futuro indefinido. Bajo los créditos UVA, la dinámica inflacionaria se internaliza con la variación del

\footnotetext{
${ }^{5}$ El terreno deberá cumplir como mínimo con los estándares previstos por el Ministerio del Interior, Obras Públicas y Vivienda.
} 
precio de la UVA, lo que permite al banco ofrecer una tasa de interés más baja. De esta manera, la tasa de interés de un crédito en UVA se define como UVA más un porcentaje determinado anual (Tessmer, G. y otros: 2018).

Hasta fines del 2017, la tasa fija era muy baja en el mercado financiero, partiendo desde el 3,5\% hasta 8,5\%, pero luego en el 2019 se duplicaron encontrándose entre 7\% a $15 \%$. De esta manera, inicialmente el beneficiario pagaba una cuota que equivalía a menos de la mitad que si lo hiciera a tasa fija o al valor de un alquiler. Cabe señalar que la cuota calculada no debe superar el $20 \%$ del ingreso neto para el destino construcción y del 25\% para los restantes destinos (Barenboim, 2019).

A la disponibilidad de estos préstamos, se sumará la posibilidad de ofrecer instrumentos para la captación de depósitos denominados en UVA de entre 90 y 180 días. De esta forma, existe la posibilidad de emitir títulos o valores denominados en UVA, con o sin oferta pública, por plazos no inferiores a dos años.

\section{EVALUACIÓN DE LOS CAMBIOS DURANTE SU GESTIÓN Y SUS ADAPTACIONES EN ROSARIO}

En los cuatro años de vigencia del crédito se atravesaron diversos y cuantiosos factores de riesgo, tanto internos como externos. En relación a los primeros, el incremento en la tasa fijas y unidades de medida, prácticamente dos veces y media, representa peores condiciones crediticias para los tomadores. En sus inicios en el 2016, la tasa era muy baja para promover la operatoria. Por ejemplo el Banco Nación (2019) ofrecía para sus clientes hipotecarios tasa fija anual a 3,5 \% + UVA, cuyo valor base era $\$ 14.05$. En el mismo mes del 2019 la tasa de interés se incrementó a $10 \%$ y el valor del UVA paso a $\$ 35,10$.

El impacto en la suba de tasas fijas tuvo incidencia pero la variación en el tipo de cambio junto a la inflación, vinculadas a factores externos, fueron las principales variables que impactaron en el crédito UVA. La variación anual de la unidad UVA tuvo un comportamiento similar al de la inflación, presentándose la mayor diferencia en el año 2016 con 6,7 puntos, siendo siempre mayor el valor de la inflación que el de la unidad UVA. Asimismo, desde el inicio la devaluación de la moneda local fue significativa, prácticamente duplicando su valor en el 2018. 
Tabla 1. Porcentaje de la variación anual: Tasa Fija, UVA, Inflación y Dólar

\begin{tabular}{|c|c|c|c|c|}
\hline Año & Tasa fija BN & UVA & Inflación & Dólar \\
\hline 2016 & 0 & 22.8 & 29.5 & 8.1 \\
\hline 2017 & 85 & 22.5 & 24.8 & 17.37 \\
\hline 2018 & 123 & 46.8 & 47.6 & 209 \\
\hline 2019 (1 ${ }^{\text {erTrim) }}$ & 125 & 6 & 11.8 & 10.5 \\
\hline
\end{tabular}

Fuente: elaboración propia en base a datos del BCRA y INDEC, 2019.

Al mismo tiempo, hay un desajuste con otro factor externo como es la evolución del salario real. Al respecto Camusso, Thailinger y Villaggi (2018) señalan que el desacople entre inflación y salarios es un gran problema que se vislumbra ya que el ajuste de la unidad de cuenta en un contexto inflacionario incierto provoca efectos redistributivos entre deudores y acreedores. De esta forma, las variaciones del salario real pueden causar un incremento en la relación cuota-ingreso, por lo que la clave sería quebrar los signos heredados de la historia económica argentina: volatilidad y crisis reiteradas.

A pesar de que los parámetros se ajusten en torno a la evolución del poder adquisitivo, debido a que las cuotas son fijas en UVA, se establecen límites en la relación cuota/ingreso permitiendo al usuario la posibilidad de renegociar plazos si esta relación excede el $25 \%$, extendiendo cada vez más el crédito, dado que hoy están muy por encima de ese monto. Es decir, si al comienzo la deuda se había contraído por 20 años luego, debido al encarecimiento del UVA y las tasas de interés, se dificulto su pago ofreciendo el banco extender el tiempo a un máximo de 30 años.

Posteriormente se incorpora una cláusula que cuantifica esto. Si la inflación supera en 10 puntos al salario, el beneficiario puede extender el plazo, es decir el número de cuotas originalmente previstas. El banco no aumentará la cuota, lo que correspondería si actualizara por UVA, sino que dejara para más adelante la deuda y cobrará la diferencia cuando el índice salarial supere al incremento de precios. Si el salario va a la par de la inflación, la cuota y el capital mantendrán la misma proporción (Llenas, 2017).

Debido al contexto macroeconómico actual (inflación, suba de los precios en general, pérdida del empleo, etc.) y los desmedidos incrementos de las tasas fijas y unidades de medida anteriormente mencionados gran parte de los beneficiarios terminan extendiendo los plazos o en el peor de los casos 
no pudiendo pagar las cuotas. El capital se va indexando de tal forma que es alarmante. Por ejemplo el abogado Luciano Tamous, de la Asociación de Defensa al Consumidor (ADC) explica que:

\begin{abstract}
"Si vos sacas un crédito por 1 millón de pesos y vas pagando las cuotas durante doce meses, un año después es como si no hubieses pagado nada. Te vas a dar cuenta que el capital sigue aumentando, no impactando ninguno de los pagos que hiciste e incrementándose el capital en una forma sideral. Esto va a generar imposibilidades de $\operatorname{pago"}^{6}$ (Cándido, 2018).
\end{abstract}

Es por ello que se presentaron dos proyectos de ley a nivel nacional en la Cámara de Diputados que intentan proteger a los destinatarios. Por un lado, el de Mónica Maya que menciona que los créditos se indexen por el índice salarial y no el de inflación, y por el otro, el de Marcos Lavagna que incluye la activación de un "Fondo Fiduciario de Compensación Hipotecaria" con el fin de blindar los préstamos, respetando que la relación cuota ingreso nunca aumente por encima del nivel que tenía en la primera cuota. Al respecto Lavagna (2018) expresa que cuando los sueldos le ganan a la inflación el banco destina al Fondo una parte de la cuota, mientras que si se dispara la inflación por encima de los salarios el Fondo utiliza el dinero acumulado para garantizar que la cuota no aumentará más de lo que aumentan los sueldos, protegiendo al deudor.

Además el bloque de senadores justicialista presenta un tercer proyecto que se ajusta por una combinación del Índice de Precios al Consumidor (IPC), que releva el INDEC, y una tasa nominal anual fija. La cuota del préstamo será del promedio entre el IPC y la tasa anual. Proponen crear el "Programa de Protección de Deudores de Préstamos Hipotecarios en Monedas Indexadas" con el objetivo de proteger a los deudores hipotecarios del riesgo de "descalce" entre los ingresos y la inflación.

Al mismo tiempo, se presentó a nivel provincial una propuesta en la Defensoría del Pueblo de Santa Fe, que establece la moderación al máximo posible de la tasa de interés por sobre el incremento que tiene el UVA. Asimismo, insta a las autoridades nacionales y las entidades bancarias a evitar intimaciones a los deudores conminando a prorrogar plazos o renunciar a esa posibilidad. Propone además en forma voluntaria e individual reducir la cantidad de UVA que se abona mensualmente, producto de comparar la relación de ingresos actuales con la que se tomó el crédito, hasta encontrar el equilibrio inicial (Rosario3, 2019). Es decir que se vuelve a la relación cuota/ingreso que tenía cada

${ }^{6}$ Entrevista realizada a Ariel D’ Orazio Coordinador de Concejalía Popular, 15/04/18. 
familia al momento que se tomó el crédito, por ejemplo si una familia tenía afectado el $25 \%$ al pago de la cuota se pide que vuelva a ese valor.

Sin embargo el gobierno nacional no les dio curso a ninguna de estas propuestas, dejando librada a su suerte a las familias que destinaron sus ahorros para obtener su vivienda única e inclusive pudiendo vender las hipotecas de los deudores.

La ley 24.441, en su capítulo 6, trata la ejecución de títulos hipotecarios. Sostiene que la hipoteca no es sólo un trato con el banco, lo que implica que pueden negociar la deuda en el sistema financiero, vendiendo el título de la propiedad. El banco tiene la posibilidad de transferirlo sin notificar al deudor. Esta ley establece la ejecución extrajudicial de la propiedad hipotecada, que no necesita un juicio para ejecutarla. Se ejecuta y después se discute. La única defensa que tiene un deudor es pagar todo.

Particularmente en Rosario, más de 100 beneficiarios se unieron, conformando el grupo "Hipotecados UVA Santa Fe (Seccional Rosario)"7, para intentar que el Gobierno Nacional controle los valores de las cuotas que los deudores deben abonar de forma mensual e impida la venta de las hipotecas a entidades financieras. Uno de los miembros, Gonzales, en diálogo con la periodista Luchessi de radio Sí 98.9 señala que

\begin{abstract}
“Nosotros no somos inversores, ni compramos ni vendemos propiedades. Simplemente queríamos cumplir el sueño de la casa propia y terminamos estafados (...) con la inflación desmedida, uno termina debiendo más de lo que valen las propiedades en sí (...) no estamos pidiendo no pagar o que el crédito se licúe, es que se indexe por algo razonable como el índice de aumento salarial".
\end{abstract}

Por último, en el campo normativo, hubo modificaciones que apuntan a facilitar la financiación de los proyectos inmobiliarios en su "etapa inicial", los cuales cuentan con una serie de etapas (diseño, aprobación, construcción y subdivisión) que incrementan los precios de las unidades en su "etapa final", resultando más difícil el acceso a la vivienda.

\footnotetext{
${ }^{7}$ La iniciativa tiene su réplica en otras ciudades del país como La Plata, Mendoza, Córdoba y en algunas localidades de la provincia de Buenos Aires.
} 
En este sentido, las adecuaciones en las clases de garantías "Preferidas B", incluidas en las Normas de Liquidez y Solvencia (LISOL) del BCRA, tienen un fuerte impacto en el régimen de clasificación de deudores. Al respecto Durini (2019:1) resume los siguientes conceptos:

- $\quad$ Considerar como equivalente a una hipoteca en primer grado, a los derechos decobrocon la mejor prelación respecto de los demás acreedores, que se establezca a favor de la entidad financiera prestamista en el contrato de fideicomiso que contenga entre sus activos el inmueble sobre el cual se desarrollará el proyecto;

- Incorporar al fideicomiso degarantía como Garantía Preferida B, entanto se constituya para respaldar el pago de la financiación otorgada por una entidad financiera para la construcción del inmueble y se cumplan con ciertos requisitos allí establecidos;

- Incorporar la cesión fiduciaria de boletos de compraventa sobre futuras unidades funcionales a construirse o en construcción, respecto de las cuales no es posible otorgar posesión, en tanto el boleto esté inscripto en el Registro correspondiente; e

- Incorporar la prenda o cesión en garantía de derechos sobre desarrollos inmobiliarios implementados a través de fideicomisos o sociedades constructoras, sujeto al cumplimiento de ciertosrequisitos.

Las reformas a esta normativa consideran las previsiones mínimas por riesgo de incobrabilidad que deben efectuar los bancos (públicos o privados) que otorgan los préstamos hipotecarios. Agrega Durini (2019:1) que "... las financiaciones que cuenten con cobertura de garantías preferidas obligan a efectuar menores previsiones por riesgo de incobrabilidad, moderando con ello el efecto negativo que provoca la incobrabilidad de créditos en los patrimonios de las entidades financieras".

En suma, los cambios macroeconómicos del país juntos a los propios del sistema de financiamiento, hicieron que el crédito resulte inviable, debiendo el Estado buscar o elegir algunas de las alternativas propuestas por los gobernantes. Todas coinciden y remarcan la imposibilidad de pago en estas condiciones, evidenciando el gran desfasaje entre la cuota/ingreso, debiéndose revisar el cálculo de la cuota mensual. Asimismo, la mayoría de los créditos fueron otorgados por bancos públicos pudiendo ser más factible encontrar una solución desde el ámbito gubernamental. 


\section{ALCANCE EN LA CIUDAD DE ROSARIO}

En Rosario las propiedades se encuentran a precios altos en relación a otras ciudades del país por lo que es un buen momento para vender, pero no para comprar. A pesar de la devaluación de la moneda, los inmuebles mantienen sus valores en dólares. El precio está sujeto a los cambios del valor de la divisa, resultando cada vez más difícil su acceso. ${ }^{8}$ Asimismo, no se llegaron a tasar por unidad de valor adquisitivo (UVA) en el mercado inmobiliario.

Contrariamente, a la tasación de las propiedades en dólares, el crédito UVA está conformado en pesos argentinos y se actualiza por la inflación, lo que produce que el beneficiario tenga el problema en algunos casos de que no puede comprar la misma propiedad que al inicio del sistema eligió. Al respecto Martinucci expresa que "... las ventas de las propiedades son en dólares y el crédito es en pesos, cuando el dólar subió las familias no pudieron hacerse cargo. Había un desfasaje entre la selección de la propiedad, que a veces la señaban, y la liquidación del crédito". ${ }^{9}$ Es decir que al mismo valor para comprar una propiedad en dólares hoy se debe pedir una cantidad prestada de dinero mayor y tener un nivel de capital propio mayor (ahorros) que si hubiese realizado su transacción al inicio.

La oferta de inmuebles aptos para el crédito es amplia, principalmente en las modalidades de compra y de cambio referidas a viviendas usadas. Hay una gran disponibilidad de inmuebles debido a que se continuó invirtiendo en la construcción, especialmente en unidades de pequeñas dimensiones, durante la última década. Al mismo tiempo la cantidad de inquilinos creció, es decir una parte de la demanda potencial de créditos. La proporción de hogares habitados por propietarios de la vivienda y terreno es de $66 \%$ (211.500 hogares) y propietarios de vivienda solamente es de 5,3 \% (16.977 hogares), con relación al total representan al 71,3\%, mientras que los inquilinos constituyen el 18,8\% (60.388 hogares) para el año 2010, según datos del INDEC. En ciudades como Rosario en donde los alquileres pueden llegar a representar más de un 30\% del ingreso medio, obtener la propiedad sobre una vivienda dignifica al hogar y le otorga una seguridad jurídica y económica (Barenboim y Brizuela, 2017).

\footnotetext{
${ }^{8}$ En Argentina se valúan las propiedades y se realizan las operaciones inmobiliarias en dólares.

9 Entrevista realizada a contador público Daniel Martinucci titular de GAMA Inmobiliaria y miembro de las Comisiones Directivas de la Cámara de Empresas Inmobiliarias de Rosario (CADEIROS) y de la Federación Inmobiliaria de la República Argentina (FIRA), 15/04/19.
} 
Entre los años 2016 y 2019, se otorgaron 16.000 créditos hipotecarios en la provincia de Santa Fe. Rosario fue una de las ciudades más consumidoras del país, estimándose una cifra de 8.500 solicitudes. ${ }^{10}$ No se publicaron datos sobre cuántos son en cada una de las cuatro modalidades (adquisición, cambio, construcción, ampliación). La evolución fue heterogénea en el tiempo, teniendo su mayor auge en los dos primeros años y su declive en los dos últimos.

El programa arranco en forma más tenue en el 2016 (teniendo en cuenta que la tramitación del crédito suele demorar varios meses) y se consolidó en el 2017, en donde hubo una gran demanda con la mitad de las propiedades vendidas bajo esta modalidad, según explicó el presidente de la Cámara de Empresas Inmobiliarias de Rosario José Ellena (Cándido, 2018).

El crecimiento fue exponencial, desplazando a las líneas tradicionales de créditos e incluyendo a tomadores nuevos, que no calificaban para la oferta crediticia previa al lanzamiento de las unidades UVA. Además, al principio la oferta fuerte era en los bancos públicos en Rosario. Agrega Martinucci que

\begin{abstract}
“... la mayoría de las ventas que se hicieron en la ciudad fueron con el Banco Nación, específicamente con sus clientes que obtenían cuotas más bajas (...) estaba mejor preparado que otros bancos dado que tiene oficinas organizadas $y$ personal competente, desde hace mucho tiempo que trabaja con créditos hipotecarios. Contrariamente hubo problemas con otras entidades financieras, no estaban organizadas y había un desfasaje entre la entrega de documentación y la escritura"11
\end{abstract}

De a poco fueron tomando mayor protagonismo los bancos privados, que según la Defensoría del Pueblo (2019), “... comenzaron a ofrecer plazos más extensos, más capital y opciones crediticias relacionadas a la unidad UVA. La entrada vigorosa en el mercado de los bancos privados demostraba el atractivo comercial para la propia banca: principalmente dada la rentabilidad asegurada a través de la unidad UVA". Igualmente cabe mencionar que la mayoría de los préstamos se dieron en los bancos públicos, específicamente el Banco Nación, ya que el Municipal no los otorgo y el Provincial solo dio unos pocos para funcionarios.

\footnotetext{
${ }^{10}$ Entrevista realizada a realizada a González Diego integrante del grupo Hipotecados UVA Santa Fe (Seccional Rosario), 10/05/19.

11 Ídem 9.
} 
En el 2018, debido a la fuerte devaluación de la moneda, que alcanza su pico máximo en septiembre cuando la cotización oficial suma $\$ 41,25$, y la creciente inflación anual, que llego a 47,6 \% (Banco Nación, 2019) representando la cifra más alta de las últimas décadas, las ventas inmobiliarias en general se redujeron en Rosario.

Consecuentemente la suba de la inflación impactó en forma directa en el índice CER, incrementando el valor de las unidades de medida UVA. Además, no se pudo detener el incremento de las tasas de interés que realizaron todos los bancos. Sumado a eso, la caída del nivel de empleo, un significativo retraso salarial, el incremento de los impuestos y servicios junto a los precios en general, entre otras variables macroeconómicas, hicieron que la demanda se desacelere, no habiendo prácticamente solicitudes y escasas consultas para el 2019. Al respecto Ariel D’Orazio de Concejalía Popular expresa que

\begin{abstract}
"Este incremento bajo las expectativas porque dejó de ser un producto atractivo para una clase trabajadora por tener ese doble componente. Por un lado, una cuota fija se dispara en más del 100 por ciento (...). Por otro, cambian las condiciones para los que están tramitando el crédito. Es una locura cambiar las condiciones prepactadas". ${ }^{12}$
\end{abstract}

Los prototipos de viviendas generalmente son unidades habitacionales (casas o departamentos) que se ofrecen en el mercado inmobiliario, monoambientes, de uno o dos dormitorios, con cocina, living-comedor, baño, patio y/o balcón, contando con cochera en algunos casos, pudiendo ser nuevas o usadas sin importar la antigüedad. Las superficies arrancan en los $17 \mathrm{~m}^{2}$ hasta los $110 \mathrm{~m}^{2}$ aproximadamente y se localizan en distintas zonas de Rosario, principalmente en el Área Central, en el Primero y Segundo Anillo Perimetral. ${ }^{13}$ Al respecto Martinucci dice que "... la mayoría de las ventas son para unidades terminadas pudiendo comprar, ampliar o refaccionar una vivienda única dentro de la ciudad a diferencia del crédito Pro.Cre.Ar. que su mayoría era para construir en la periferia". ${ }^{14}$

\footnotetext{
${ }^{12}$ Entrevista realizada a Ariel D' Orazio Coordinador de Concejalía Popular, 15/04/18.

${ }^{13}$ El Área Centra está comprendida por el bulevard Oroño, la avenida Pellegrini y el río Paraná. Contiguamente se encuentra el Primer Anillo Perimetral, delimitado por los bulevares Oroño, Francia y las avenidas Pellegrini y 27 de Febrero mientras que el Segundo Anillo Perimetral esta entre los bulevares Francia y Avellaneda y las avenidas 27 de Febrero y Seguí.

14 Ídem 9.
} 
Las inmobiliarias más reconocidas de la ciudad, como ser Propiedades Uno, Furigo, Bauen Pilay entre otras, dentro de sus sitios webs y/o publicidades, promocionan "propiedades apta crédito hipotecario" cuando el monto es acorde al préstamo UVA (ver Imagen 1 y 2).

Imagen 1. Propiedades ofrecidas aptas créditos UVA en Rosario
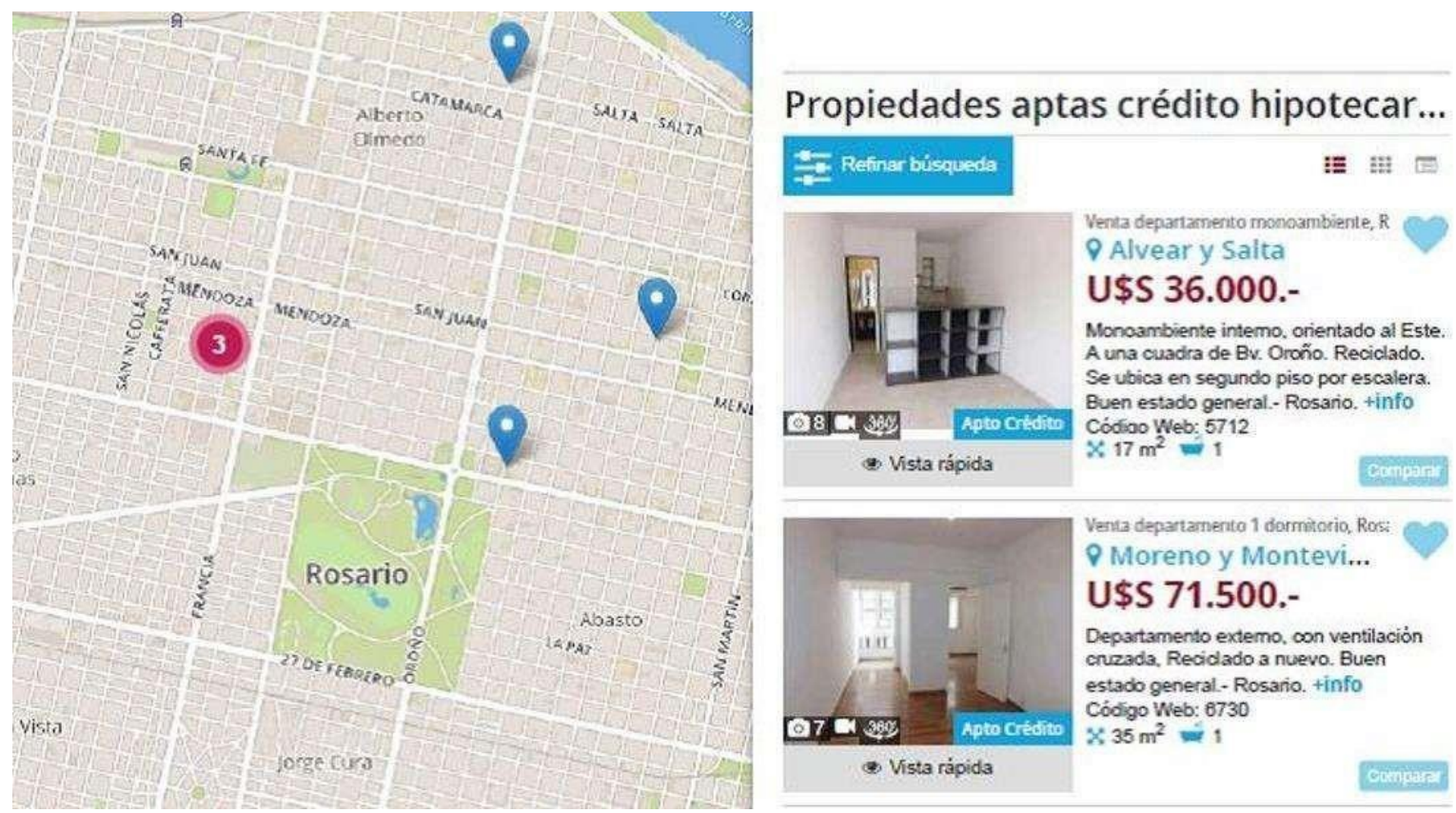

Fuente: Dunod Propiedades, 2019.

Imagen 2. Propiedades ofrecidas aptas créditos UVA en Rosario 

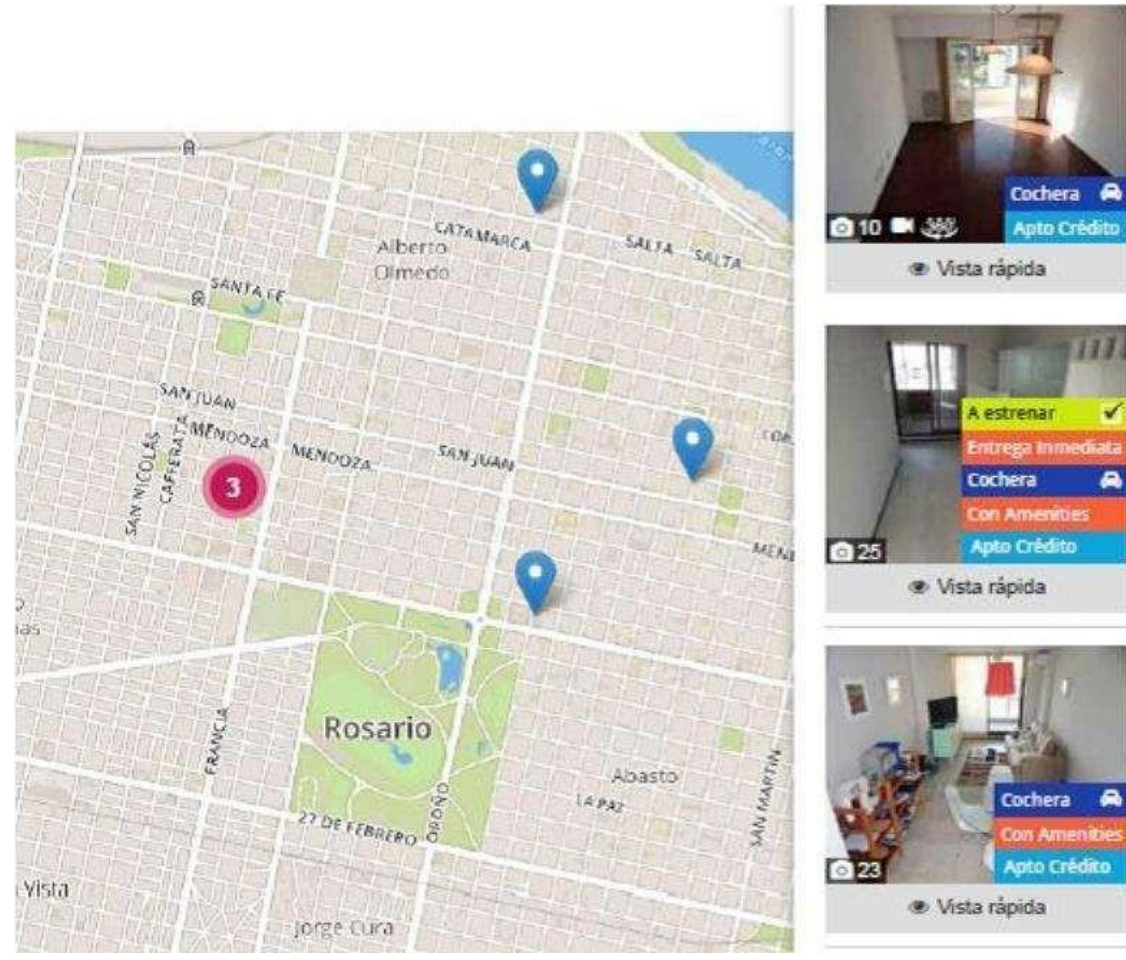

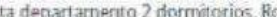
P Paraguay y San Luis

U\$S 128.000.-

Departamento extemo crientado al Este, completamente recidado con ventilación completa Con mplio comida de $2 \mathrm{~m}^{2}$, baulera y corna ind. en valor). En la terraza hay un SUM. $\$ 110 \mathrm{~m}^{2}=2$ Si

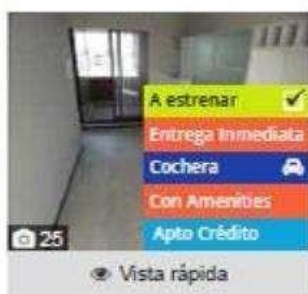

Venta departamento 2 dormitorios, Rot Q 9 de Julio y Vera M...

Increible semipiso externo a estrenar. con ventilación crizada, entrega con ventiacion cruzada, entrega MMEDIATA. Extraordinaria ubicación Av. Francia. Edificio con quincho $\mathrm{X} 99 \mathrm{~m}^{2}=1 \mathrm{mi}$

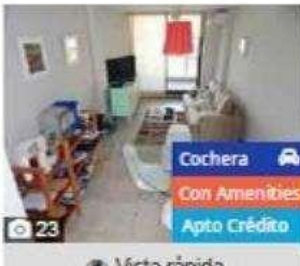

Venta departarnento 2 dormitorios, Ro: Q 9 de Julio y Vera M...

Departamento externo, con ventilación cruzada, ALQUILADO. Extraordinaria ubicación muy cerca de las avenidas Pellegrini y Av Francia Cercano al parque in $\times 89 \mathrm{~m}^{2}=10 \mathrm{Si}$

- Vista rápida

Fuente: Dunod Propiedades, 2019.

Del mismo modo, otras inmobiliarias locales, como Dunod propiedades, tienen un sector que dice "calcula el préstamo hipotecario" en donde simula la cuota a partir de datos del interesado (dirección, fecha de nacimiento, ingresos, antigüedad laboral, sumatoria con otro salario y destino del crédito), que se completan en un formulario online.

Por su parte, las empresas constructoras tuvieron reuniones con el Banco Nación y la Cámara de Construcción para poder aplicar la modalidad, sin embargo el procedimiento para venta en pozo con crédito, por el momento no se puede aplicar. Bertoni expresa que: “Uno de varios motivos, es que no existe un derecho real como sucede en propiedades usadas, donde la garantía es la escritura. En un edificio en pozo no se cuenta escritura por lo tanto el banco no tiene garantías de cobro". ${ }^{15}$

\footnotetext{
${ }^{15}$ Entrevista realizada a realizada a Luciano Bertoni encargado del área comercial de Pascual Construcciones, 08/05/19.
} 
Los usuarios más comunes en la ciudad son parejas jóvenes que tienen un promedio de 38 años y adquieren una deuda de 22 años, a partir de la solicitud de un préstamo de $\$ 1.500 .000$ en el 2016 que se incrementa a $\$ 3.760 .000$ para el 2019 (Barenboim, 2019).

\section{CONCLUSIONES}

La forma de financiación crédito UVA se implementa en el marco de una política monetaria basada en una inflación moderada, intentando regular el incremento de los precios y estableciendo metas creíbles en la evolución del poder de compra de la moneda nacional.

Durante los dos primeros años (2016 y 2017) esto permitió el crecimiento del stock de créditos hipotecarios ampliando el mercado financiero e inmobiliario en la ciudad de Rosario. Las condiciones crediticias, el interés y los plazos, eran consistentes con la evolución del contexto macroeconómico, teniendo un mayor protagonismo los bancos públicos. Las cuotas eran accesibles, similares a los montos de un alquiler y menores a la de los créditos tradicionales.

En los dos últimos años (2018 y 2019) las condiciones crediticias empeoraron: incremento de tasas de interés de todas las entidades bancarias y la variación de las unidades UVA desde su inicio (Banco Nación tasa 3,5 \% y UVA \$14,05 en marzo de 2016; tasa $10 \%$ y UVA $\$ 35,04$ en abril de 2019). Sumado a que las propiedades mantuvieron su valor en dólares, aumentando su valor en pesos con la fuerte devaluación de la moneda. Esto requirió un mayor ahorro previo y préstamo, no habiendo consultas en la ciudad.

Asimismo, la suba de los precios en general, el incremento de los servicios e impuestos, la fuerte pérdida salarial, el desfasaje con la evolución de precios y los salarios, entre otros factores externos redujo el mercado crediticio, expulsando inclusive a los posibles tomadores de créditos. Sin embargo, la situación más preocupante es la de familias que han tomado los créditos UVA y no pueden pagarlos, pudiendo perder sus viviendas.

Lo antedicho demuestra la vulnerabilidad de este tipo de instrumentos a variaciones bruscas, principalmente en la tasa de inflación que afecta directamente al coeficiente de ajuste de las UVA, requiriendo que la evolución del ingreso vaya a la par de la inflación. Es decir que para tomar estos préstamos no sólo es necesario una estabilidad financiera personal y/o familiar sino que el contexto macroeconómico influye directamente en el crédito a pagar. 
En consecuencia, se han presentado proyectos de ley, una propuesta provincial y organizado grupos, en Rosario y en las principales ciudades del país, que intentan regular el desmedido aumento de las cuotas contemplando otras variables de indexación, siendo la principal el coeficiente de variación salarial (CVS).

En suma, los nuevos créditos hipotecarios parecían ser una política proclive a garantizar el acceso a la vivienda para los sectores medios, pero terminó siendo lo opuesto "un sistema especulativo de los prestamistas" en donde el Estado está ausente. Lo antedicho demuestra la importancia que tiene el gobierno para regular dicha situación, siendo necesario que brinde una respuesta acorde a las posibilidades reales de pago de los beneficiarios y termine con la especulación financiera.

La mayoría de los créditos fueron otorgados por bancos públicos pudiendo ser más factible encontrar una solución desde el ámbito gubernamental. El Estado cuenta con todas las herramientas para poder solucionar el conflicto, como, por ejemplo: subsidiar el desfasaje entre la cuota/ingreso, limitar a los bancos las tasas de interés fijas volviendo a los valores iniciales del 3,5\%, actualizar la cuota y no el capital acumulado, entre otras posibles propuestas.

De forma contraria, el crédito se transformará en "una deuda perpetua" impactando fuertemente en la clase media, siendo cada vez más difícil cumplir con el tal anhelado derecho a la vivienda.

\section{BIBLIOGRAFÍA}

ARBIA, Carlos. Boom de créditos hipotecarios: cuáles son los requisitos, montos, plazos y cuotas en Diario Infobae, Rosario, Marzo de 2017. Recuperado de:https://www.infobae.com/economia/2017/03/05/boom-de-creditos-hipotecarios-cuales-son-losrequisitos-montos-plazos-y-cuotas/

BARENBOIM, Cintia Ariana. Financiamiento del mercado de viviendas: créditos UVA en Rosario, en 4to Congreso Latinoamericano de Estudios Urbanos. Buenos Aires: Instituto del Conurbano - UNGS, Octubre de 2019.

. La problemática de la vivienda y la persistencia del déficit habitacional: el caso de la ciudad de Rosario, Argentina en Revista Papeles de Coyuntura, № 43, Bogotá, 2017.

y BRIZUELA, Gonzalo. Estimaciones sobre la realidad habitacional en el Departamento Rosario, en $X$ Jornadas de Economía Crítica. Buenos Aires: Universidad General Sarmiento, Septiembre de 2017. 
BANCO NACIÓN. Créditos UVAS en simples pasos. Buenos Aires: Banco Nación, 2019.

Recuperado de: https://www.bna.com.ar/Personas/CreditosUVA

BARRETO, Miguel. El concepto de hábitat digno como meta de una política integral de áreas urbanas deficitarias críticas, para la integración social desde los derechos humanos en Revista INVI, Vol. 25, N 69, Santiago de Chile, 2010.

CAMUSSO, Jorge; THAILINGER, Agustina y VILLAGGI, Agustina. Breve análisis de los nuevos créditos hipotecarios UVA. Rosario: Banco Municipal, 2018.

CÁNDIDO, Paola. El aumento de créditos UVA pegara fuerte en Rosario en El ciudadano. Rosario, Abril 2018. Recuperado de: https://www.elciudadanoweb.com/el-aumento-de-creditos-uva-pegara-fuerteen-rosario/

CELADE. Conceptos principales atinentes al déficit habitacional. Washington: ONU, 2010. Recuperado de: https://www.cepal.org/celade/noticias/paginas/9/51449/CLASES-TOTAL_Sebas2.pdf

CONGRESO ARGENTINO. Ley 24.441 Financiamiento de la vivienda y de la construcción. Buenos Aires: Presidencia de la Nación, 1995.

. Ley 27.271 Sistema para el fomento de la inversión en vivienda. Buenos

Aires: Presidencia de la Nación, 2016.

CHANCHONA ROJAS, María Adriana y DE LEON MARTINEZ. Guadalupe. Implementación de técnicas actuariales para la tarificación del riesgo de crédito hipotecario. Puebla: Universidad de las Américas, 2006.

DEFENSORIA DEL PUEBLO. Análisis de los créditos hipotecarios UVA. Buenos Aires: Programa de Estudios Tributarios e Impositivos, 2019.

DURINI, Federico. Novedades recientes para fomentar el desarrollo del mercado

Inmobiliario en Abogados. Rosario, Abril $2019 . \quad$ Recuperado de: https://www.abogados.com.ar/novedades-recientes-para-fomentar-el-desarrollo-del-mercadoinmobiliario/23218 
ESPER, Mariano. Unidades UVI y UVA que son y por qué existen, en diario La Nación. Buenos Aires, Enero 2018. Recuperado de: https://www.lanacion.com.ar/propiedades/unidades-uvi-y-uva-que-sony-por-que-existen-nid2102225

GARGANTINI, Daniela. Sistemas de registro de demanda habitacional y políticas locales de hábitat: resultados de la encuesta nacional 2014. Buenos Aires: Secretaría de Asuntos Municipales, 2015.

GONZALEZ, Diego. No planteamos no pagar sino una indexación acorde para los créditos UVA en Radio Sí 98.9. Rosario, Febrero 2019. Recuperado de: https://soundcloud.com/si989rosario/nep-dgonzalez-no-planteamos-no-pagar-planteamos-una-indexacion-razonable

HARVEY, David. Rebel cities: From the right to the city to the urban revolution. London: Verso, 2012.

INDEC. Censo Nacional de Población, Hogares y Viviendas para la ciudad de Rosario. Buenos Aires: Ministerio de Hacienda de la Nación, 2010.

LAVAGNA, Marcos. El Frente Renovador impulsa un proyecto de Ley para proteger a los tomadores de créditos UVA en Ámbito Financiero. Buenos Aires, Marzo 2018. Recuperado de: https://www.ambito.com/el-frente-renovador-impulsa-un-proyecto-ley-proteger-los-tomadores-delcreditos-uva-n4016525

LAZZARI, Ricardo. El déficit habitacional en la Argentina: estimación para el año 2009. Buenos Aires: FODECO, 2012.

LLENAS, Rubén. Financiamiento alternativo. Herramientas para la generación de políticas que promuevan el acceso a la vivienda y mejoren el hábitat en Transformaciones del espacio urbano y gestión de la ciudad. Rosario: Consejo Económico y Social, 2017.

PAREDES, Débora y otros. La clase media Argentina y su realidad en relación al acceso a la vivienda en Revista Facultad de Derecho, №179, Rosario, 2014

PÉREZ BARREDA, Natalia. Acceso a la Vivienda y al Hábitat. Formas de financiamiento a la Vivienda y experiencias integrales de planificación e intervención territorial. Rosario: Instituto de Gestión de Ciudades, 2015.

ROSARIO 3. Créditos UVA: una propuesta para atenuar el impacto de aumentos, en diario Rosario 3. Rosario, Abril 2019. Recuperado de: https://www.rosario3.com/noticias/Creditos-UVA-unapropuesta-para-atenuar-el-impacto-de-aumentos-20190430-0046.html 
Revista de Direito da Cidade

vol. 12, no 2. ISSN 2317-7721

DOI: $10.12957 /$ rdc. 2020.42232

TESSMER, German y OTROS. Informe especial créditos UVA. Rosario: Observatorio Económico Social UNR, 2018.

Trabalho enviado em 26 de abril de 2019

Aceito em 15 de maio de 2020 